\title{
Erratum: Design, synthesis and selection of DNA-encoded small-molecule libraries
}

Matthew A Clark, Raksha A Acharya, Christopher C Arico-Muendel, Svetlana L Belyanskaya, Dennis R Benjamin, Neil R Carlson, Paolo A Centrella, Cynthia H Chiu, Steffen P Creaser, John W Cuozzo, Christopher P Davie, Yun Ding, G Joseph Franklin, Kurt D Franzen, Malcolm L Gefter, Steven P Hale, Nils J V Hansen, David I Israel, Jinwei Jiang, Malcolm J Kavarana, Michael S Kelley, Christopher S Kollmann, Fan Li, Kenneth Lind, Sibongile Mataruse, Patricia F Medeiros, Jeffrey A Messer, Paul Myers, Heather O'Keefe, Matthew C Oliff, Cecil E Rise, Alexander L Satz, Steven R Skinner, Jennifer L Svendsen, Lujia Tang, Kurt van Vloten, Richard W Wagner, Gang Yao, Baoguang Zhao \& Barry A Morgan

Nat. Chem. Biol. 5, 647-654 (2009); published online 2 August 2009; corrected after print 17 September 2009

In the version of this article initially published, the $\mathrm{IC}_{50}$ values in the table in Figure $3 \mathrm{c}$ were listed as $\mathrm{nM}$ instead of $\mu \mathrm{M}$. The error has been corrected in the HTML and PDF versions of the article. 